\title{
Study on the Strategy of Customer Participation in Service Innovation in Virtual Community
}

\author{
Shi Zeng \\ School of Business Administration, South China University of Technology, Guangzhou, China \\ Email: m13163392939@163.com
}

How to cite this paper: Zeng, S. (2018) Study on the Strategy of Customer Participation in Service Innovation in Virtual Community. American Journal of Industrial and Business Management, 8, 1469-1475. https://doi.org/10.4236/ajibm.2018.86099

Received: May 8, 2018

Accepted: June 11, 2018

Published: June 14, 2018

Copyright $\odot 2018$ by author and Scientific Research Publishing Inc. This work is licensed under the Creative Commons Attribution International License (CC BY 4.0).

http://creativecommons.org/licenses/by/4.0/

\section{(c) (i) Open Access}

\begin{abstract}
With the rapid development of information technology, the relationship between people has expanded upon the real world to the virtual Internet world. A new social form of virtual community has been formed. Through virtual community, customers can communicate with enterprises to realize convenient information. Enterprises can also obtain more accurate customer needs from virtual communities, grasp the trend of market development, and improve their service innovation ability [1]. However, in reality, the degree of customer participation in service innovation in virtual communities is not ideal enough. Therefore, it is necessary to study the strategy of customer participation in service innovation under the virtual community environment. On the basis of review of literature review, this paper expounds the connotation of customer participation in service innovation, then analyzes the characteristics of interpersonal interaction in virtual communities and the main factors that affected the process of customer participation in the process of innovation in virtual communities, and puts forward the strategy of customer participation in service innovation in virtual communities.
\end{abstract}

\section{Keywords}

Virtual Community, Customer Participation, Service Innovation

\section{Introduction}

With the rapid development of the Internet, online shopping has released enormous potential, which has undoubtedly become the fertile land for the development of virtual communities. At the same time, consumers are becoming more and more autonomous. They are gradually shifting from passive acceptance of products or services to their own needs, and even in the innovation activities of the enterprises [2]. The research of Franke and Shah [3] found that 
$23 \%$ of the customers' creativity has the potential of commercial application and can create greater value for enterprises.

And the difference between physical products is becoming smaller and smaller. It is difficult to separate the product of the peers only by product differentiation. In order to maintain competitiveness, enterprises need to continuously carry out service innovation and establish their own competitive advantages in service. In the virtual community, customer needs are diversified and the behavior is free. In order to understand the nature of the service more accurately, it has become crucial to develop a set of strategies to guide companies in customer participation in service innovation in virtual community [4].

By researching the strategies of customer participation in service innovation in virtual communities, it is possible to enhance the cognition of the customer's participation behavior, and clarify the main features of customer participation and the importance of customers for enterprise knowledge acquisition, so that enterprises can realize the importance of customers in service innovation. Enterprises can formulate corresponding incentive mechanisms to attract more capable customers to participate in service innovations to enhance their customer loyalty and brand effect; and to promote changes in corporate innovation models and thinking.

Next, this article will be divided into four parts. First of all, combing and summarizing the connotation of customer participation in service innovation, the characteristics of interpersonal interaction in the virtual community and the main factors affecting the customer participation in the innovation process in the virtual community. Then, based on the above discussion, this paper creatively proposes a strategy for customer participation in service innovation in virtual communities. Finally, the limitations of this paper and the prospects for the future are discussed. It is hoped that this will provide beneficial thinking for customer participation in service innovation.

\section{The Connotation of Customer Participation in Service Innovation}

Magnusson [5] summed up the concept of "customer participation in service innovation" as: cooperation between service companies and customers in service innovation process, through the development of innovative services to meet the customer's potential needs. Carbonell [6] pays more attention to the communication and cooperation in all stages of the service innovation process, and expands and emphasizes the stages in which customers participate in the development of new services. Customer-involved service innovation is defined as: At each stage of new service development, people that produce services interact with one or more existing (or potential) customer representatives.

Lu Junyi and Wang Yonggui [7] believe that "customer participation in service innovation" refers to the exchange and cooperation between service enterprises and customers in the development of services at all stages of the develop- 
ment of new services.

Therefore, by reviewing previous research results, we can define "customer participation service innovation" as: In order to meet the needs of their own, customers participate in the process of enterprise service innovation activities. In each stage of the service process, the customer's time, intelligence and power input have an impact on the service transformation and the new service [8].

\section{The Characteristics of Human Interaction in Virtual Community}

Before studying the virtual community customers' participation in service innovation, we must first understand the characteristics of human interaction in the virtual community. Although the virtual community and the real community are groups composed of people, the virtual community surpasses the real community and has the characteristics of non-realistic contact, Interactivity and openness, and self-organization.

\subsection{Non-Realistic Contact}

The virtual community is based on the Internet. People have changed face-to-face, telephone communication and other monotonous traditional service contact methods, and began to make use of the Internet to complete service contact. Members cannot experience actual contact in the virtual space, and they can only rely on the information network to maintain interaction with other community members. This makes interpersonal communication have certain obstacles and affects the efficiency of interaction. At the same time, the accuracy of capturing real customers' needs in the virtual community will also decrease [9]. Therefore, the choice of participating customers and the improvement on management of customer knowledge has become extremely important.

\subsection{Interactivity and 0penness}

In the virtual community, individuals and community members will form a one-to-many interaction, and thus form an extensive interactive network. These relationship interactions are reflected on two main aspects: The relationship between members and members of the community and the relationship between the virtual community operator and the members of the community [10]. The community atmosphere, the degree of trust in members, and the strength of the membership relationship all affect the frequency and cycle of interaction. At the same time, high-efficiency information dissemination technology speeds up the interaction between people, which triggers the interaction of a wider range and more types of members. This reflects the openness of this interactive relationship.

\subsection{Self-Organization}

In virtual communities, the role of members is transformed from passive posi- 
tion in active position. Community members are not merely passive recipients of information, but also act as content contributors. In self-organizing virtual communities, there may be two evolutionary trends: First, the community has shown positive changes and has developed more powerful forces. The second is that the community is showing negative changes: it cannot attract to members and then gradually deserted. By controlling the evolution of poor self-organization, enterprises can effectively promote the openness of the community and give full play to the creativity of the members.

\section{The Main Factors Affecting Customers' Participation in the Innovation Processes in Virtual Communities}

Only by understanding the main factors influencing the customers' participation in the innovation process in the virtual community, can we put forward strategies to improve customer participation in innovation in line with local conditions. Therefore, each of the influencing factors will be presented one by one.

\subsection{Customer Traits}

Customer involvement refers to the customer's level of investment in emotional and intellectual innovation activities. Most of the existing research thinks that the degree of customer involvement will have a positive impact on service innovation. Zhang Hongqi and Lu Ruoyu [7] believe that customers should be encouraged to participate in the service innovation process, and customers should be able to act as sponsors, practitioners and proliferators of innovation activities. However, customer involvement may also create uncertainty of innovation activities. This uncertainty is reflected on the difference in demand and the inaccuracy of market information. There may also be situations in which the ability of customers is different and they cannot participate in innovation activities.

\subsection{Interactive Traits}

The sense of community identity has played an important role in enabling virtual communities to develop members of loyal users [11]. The atmosphere of the community will affect the customer's sense of community identity. This will affect the close relationship between customer and business innovation interactions. The influence of community identity on innovation activities is divided into two situations: On the one hand, it affects the enthusiasm for customer participation. A good community atmosphere will allow customers to have enough love for the virtual community and trigger a strong desire for service improvement. On the other hand, it will also encourage customers to share knowledge with the company and thus influence the process of innovation.

\subsection{The Function of the Company}

Customers need to gain knowledge from the company and allow customers to innovate from the perspective of the company. Therefore training is of impor- 
tance. The enterprise's training, guidance and management of customers can have a positive impact on the service innovation of the company. On the one hand, the concept of the company can be deeply rooted in people's minds, reducing the customer's resistance to the product. On the other hand, customers and businesses can be fully communicated. This will increase innovation efficiency.

\section{Strategies of Customer Participation in Service Innovation in Virtual Community}

According to the nature of interpersonal interaction in virtual communities and the main factors affecting customers' participation in the innovation process in virtual communities, this paper divides the strategy of customer participation in service innovation in virtual communities into four modules, namely customer selection, customer training, customer participation, customer evaluation and incentives.

\subsection{Customer Selection}

Von Hippel (1986) divides users into leading users and general users, and emphasizes the role of leading users in innovation. Zhang Hongqi et al. (2010) classified customers into leading customers, growing customers, escaping customers, and lagging customers based on the degree of customer involvement in service innovation, the value of customers involved in innovation, and the behavioral characteristics of customers participating in service innovation. Leading customers are usually the main source of service innovation. If a growing customer is added with appropriate guidance, it will also help the service innovation of the company. For companies, how to identify and select the right customer becomes the primary issue. When selecting appropriate customers to participate in service innovation, it is mainly conducted through questionnaire surveys and competency tests.

\subsection{Customer Training}

Since the customer is not an employee of the company, it is impossible to fully grasp the skills required by the company to perform service innovation. Before participating in service innovation, several aspects of customer training are required. First of all, through organizing social participation, the customer can better recognize the company's values and business philosophy; secondly, let the customer understand the process and steps of joint service innovation; and finally, in the process of service innovation, provide training on communication and cooperation capabilities.

\subsection{Customer Participation}

\subsubsection{Create Participation Channels}

With the development and popularization of the Internet, the channels for users 
to participate in service innovation have become increasingly widespread. You can participate in the process of service innovation through user communities, forums, BBS, and Wechat. Especially during the development phase of service innovation, this all-weather, wide-coverage, and low-cost medium can motivate more consumers to participate.

\subsubsection{Make Customers Agree with the Role of Common Innovation}

In the process of customer participation in service innovation, the role of the customer has changed. Therefore, the company should help consumers to define their own role positioning and requirements. For example, the website home page clearly describes the responsibilities and steps involved in the process of customer service innovation, so that consumers will be clear that they are no longer passive recipients of innovation, but are active implementers and participants.

\subsubsection{Promote Knowledge Transfer between Customers and Businesses} In the process of customer participation in enterprise service innovation, the most important thing is how to transform the customer's knowledge into the enterprise's knowledge, especially the customer's tacit knowledge about service innovation. In order to better promote this kind of transformation, companies should establish a customer's information demand tracking mechanism and regularly track, analyze, and organize customer needs. At the same time, establish customer organizations and strengthen communication and exchange with companies.

\subsection{Customer Incentives}

The virtual community needs to establish various incentives to attract more customers to participate in service innovation activities. Because of the special nature of the virtual community, its incentive mechanism will also be different. In conjunction with other virtual communities for spiritual inspiration, we can develop economic incentives that can bring benefits of customers, promote more customers to participate in service innovation, and can also serve as a marketing campaign to a certain extent. In terms of materials, the points and ranks in the virtual brand community can be redeemed for the corresponding products and get the discount for the purchased products. In terms of spirit, it can award medals, appoint outstanding customers as community administrators, and so on. The two-tiered incentive mechanism for economic and spiritual interests will encourage more customers to participate in service innovation.

\section{Conclusion}

In summary, the enterprise service innovation in the virtual community requires a relatively high level of customer participation, but most companies currently do not have an effective customer engagement service innovation strategy in the context of the Internet. For enterprises, it can be targeted to improve the interactive mode of customer participation in service innovation, which will help com- 
panies improve service innovation efficiency and improve business performance. For consumers, they can make them more clearly aware of the benefits and value brought to them by participating in service innovation, and thus feel higher value and satisfaction. At the same time, this article also has some limitations. In the virtual community, different customer types have different effects on service innovation. Because of the wide range of participants in the virtual community, there are differences in participation motivation, personal ability, willingness, and so on. Future research can propose customer engagement service innovation strategies for different customer types.

\section{References}

[1] Nambisan, S. (2002) Complementary Product Integration by High-Technology New Ventures: The Role of Initial Technology Strategy. Management Science, 48, 382-398. https://doi.org/10.1287/mnsc.48.3.382.7724

[2] Von Hippel, E. (2005) Democratizing Innovation. The MIT Press, Cambridge, Massachusetts.

[3] Franke, N. and Shah, S. (2003) How Communities Support Innovative Activities: An Exploration of Assistance and Sharing among End-Users. Research Policy, 32, 157-179. https://doi.org/10.1016/S0048-7333(02)00006-9

[4] Campeau, D.R. and Higgins, C.A. (1995) Computer Self-Efficacy Development of a Measure and Initial Test. MIS Quarterly, 19, 189-211. https://doi.org/10.2307/249688

[5] Magnusson, P.R., Matthing, J. and Kristensson, P. (2003) Managing User Involvement in Service Innovation. Journal of Service Research, 6, 111-124.

https://doi.org/10.1177/1094670503257028

[6] Carbonell, P.R., Odriguez-Escuder, O.A.I. and Pujari, D. (2009) Customer Involvement in New Service Development: An Examination of Antecedents and Outcomes. Journal of Product Innovation Management, 26, 536-550. https://doi.org/10.1111/j.1540-5885.2009.00679.x

[7] Zhang, H.Q. and Lu, R.Y. (2010) Research on Customer Types in Service Innovation Based on Customer Participation. Journal of Electronic Science and Technology University, 12, 25-29.

[8] Silpakit, P. and Fisk, R.P. (1985) Participating the Service Encounter: A Theoretical Framework. Service Marketing in a Changing Environment, American Marketing Association, Chicago, 117-121.

[9] Fan, X.C. and Pu, T.J. (2012) Customer Participation Is a "Double-Edged Sword"-A Review of Researches on Customer Participation Impact Value Creation. Management Review, No. 12, 64-71.

[10] Ennew, C.T. and Binks, M.R. (1999) Satisfaction and Impact of Participative Service Relationships on Quality, Satisfaction and Retention: An Exploratory Study. Journal of Business Research, 46, 121-132. https://doi.org/10.1016/S0148-2963(98)00016-2

[11] Von Hippel, E. (1998) The Sources of Innovation. Oxford University Press, New York. 